\title{
The theory of cognitive visualization and its strategies
}

\section{E. Churichkanich}

Sumy state pedagogical university named after A. S. Makarenko

Paper received 19.04.18; Accepted for publication 26.04.18.

\section{http://doi.org/10.31174/SEND-PP2018-163VI67-05}

\begin{abstract}
The paper introduces the clue strategies of cognitive visualization theory reflected in leading technological methods of educational activity concepts. The pedagogical aspect of introducing cognitive graphics into the process of learning and the key problems of computerization process are taken into consideration in the article. The further investigation and implementation of new technological methods based on the theory of cognitive visualization will make learning a more effective and creative process.

Keywords: the technology of supporting facilities, the technology of increasing the density of information, the technology of conceptual core, the technology of algorithmization, the technology of multicode.
\end{abstract}

Introduction. The emergence of an independent Ukrainian state, its progressive economic development, the strengthening of the foundations of civil society require the highly effective educational system that is adequate to these ambitious goals.

It should be taken into account that as in the whole modern world, the importance of education as the key factor in the formation of an entirely new quality of the economy and public life increases with the development of the state.

The quality of life and educational potential of the Ukrainian society is determined by the level of culture of the population, its ideological orientation and spiritual development, the ability to receive and use the necessary information systematically.

We are in the sea of information that can not be systematized, turned into practical knowledge without innovative programs in the system of education.

It should be mentioned that the search for the most effective methods capable of significantly improving the quality of education is a process is now being pursued in various fields of pedagogical science.

The activation of the students learning ability on the basis of the technology of cognitive visualization of pedagogical objects is one of the clue methods aimed at solving actual pedagogical tasks.

Analysis of relevant research. It is known that in ancient times in Egyptian and Minoan hieroglyphic writing was noticed the successful use of primary cognitive-graphic models in a simplified form. The pictograms of this nature were found in Indonesia and Egypt. The investigation of the foregoing written sources was the key goal of the following scientists (S. Craft, R. Gregory, D. Hambling, L. Richardson, V. West and others) [1, p. 238].

In the theory of schemes of R. Anderson and F. Bartlett and also in frame theory of F. Folker and M. Minsky at the present stage, cognitive visualization is seen as the transfer of certain thought images from the internal plan into the external one during the process of cognitive activity.

Such well-known scientists as M. Chocnakov, K. Blutter, E. Tafty, N. Holmes, D. Wang, R. Kosara, S. Balmer, A. Kairo etc. study various aspects of modern cognitive-graphic theory.

The aim of the article is to scientifically substantiate the theoretical and methodological foundations of the potential of cognitive visualization as the basis for intensifying learning activity.

The methods of investigation are: analysis, synthesis, induction, deduction, abstraction.
Results. It should be taken into account that the verbal channel of information processing absolutely does not provide thickening and consolidation of information blocks. This task can be solved only by means of graphic constructions because information processing and concentration of ideas is usually executed by cognitive structures only at visual support.

The strategies of development of cognitive-visualization theory are different and express themselves in educational technologies that reflect the essence of leading technological methods of educational activity concepts.

Let us consider the most substantial and interesting of them.

The technology of supporting facilities is based on creation of supporting compendia, complicated blocks of frame type, mental representations, methods of graphic support of boolean operations and educational activity.

The technology helps studying to form the stereotypes of productive activity for the transfer of necessary knowledge in a new cognitive situation, to reproduce information without a book, to concentrate large volume of knowledge.

The technology of increasing the density of information includes the methods of compression, enlargement of didactic units, rolling up of knowledge in the system of coordinates etc.

The following technology simplifies work with texts, structuring semantic units in mental models, condensing educational knowledge through schematization.

The technology of conceptual core is built on semantic fractals meaningful generalizations, schemes, categoricalsemantic concepts.

The technology mentioned above promotes optimization of methods for processing large amounts of information in the shortest possible time. It allocates internal links, theoretical images obtained through mental operations with abstract objects, it also units logically heterogeneous parts into a whole at a new level of generalization. On the other hand this technology helps to reverse the analytical process of defragmentation. It is also the basis for the formation of knowledge invariants, represented in the logical-semantic models that allow to roll up whole concepts to signs, symbols and deploy learning knowledge in verbal form.

The technology of algorithmization of educational and cognitive actions which is realized in visual media by gradual formation of integral knowledge images based on the separation of elements and the relationships between them. In this technology frame structures are often used. They 
help to identify the operational component in training, they also give a set of instructions for performing certain operations, form a stereotype of actions in a standard situation.

The technology of multicode is based on simultaneous use of different forms of information designation with the help of various verbal, multimedia, visual, socialbehavioral materialized codes such as pictograms, graph schemes, didactic transformers etc.

The technology described above operates with the concepts of encoding, transcoding and decoding of information. Let us consider these concepts in more detail and scrupulously.

The concept of encoding is understood as a certain process of transforming new information with the help of adequate means of perception: specific signals and the mapping model of information.

The inverse process of interpreting the necessary information, implemented on the basis of logical associations, is interpreted as transcoding.

Semantic changes at a qualitatively higher level, changing the coding system with the conversion of one system of signals to another is decoding.

The above-mentioned technology of multicodes is used in the theory of frames, when constructing abstract summaries, structural-logical schemes, logical-semantic models.

The pedagogical aspect of introducing cognitive visualization into the process of learning is no less important. It should be mentioned that the implementation of the cognitive visualization theory is inextricably linked with the problem of computerization of any educational institution.

The ability to compose visual and other complex images significantly increases the throughput of the information channels of the learning process. The programmability of the computer, its dynamic adaptability contribute to the individualization of the learning process, preserve its integrity.

It should be taken into account that the internal formalization of the computer work, the fundamental knowledge ability of the learning strategies contribute to greater awareness of the learning process, increase its intellectual and logical levels.

The process of learning with the use of computer graphics must comply certain didactic principles, which should be considered in detail.

The principle of interactive visibility. Computer visibility allows any learner to see what is not always possible in real life by using sensitive instruments. The picture in the book makes it possible to simply see the object or phenomenon in a more detailed form, whereas with the objects presented in computer form it is possible to carry out many operations, to study the dynamics of the development of a particular phenomenon or 0bject.

The principle of individual computer accessibility is understood as an opportunity to achieve the average student's learning goals.

This principle is based on the presence in the computer of the variable paths of the training course, the various speeds of the training material, the presence of hints, the necessary auxiliary explanations for additional tasks. The computer should be set up to constantly monitor and support the motivation of each student, regardless of his level of preparation and individual abilities.
The principle of computer systemic character is built on the ability to organize educational material. Regardless of the complexity of the learning objectives, the process of studying the material must be organized systematically, in a certain sequence. The order of the issuance of training fragments of information by the training program of the computer, the definite construction, adjustment of the most effective sequence of exercises in the individual work of the trainee in intellectual educational complexes is ensured by the principle of computer systemic character.

The principle of the strategist education. A strategist considers objects and phenomena in their interconnection, he is able to independently study new material, he is ready to develop, to complement his knowledge, is aimed at constant self-development.

The trained strategist, depending on the theoretical level of the course, the complexity of concepts studied, is set the main goals and objectives of the training, and he implements them himself with the help and guidance of the computer.

The principle of dialogue between a learner and a computer. The computer, according to this principle, affects the cognitive activity of a person. Educational computer programs should be designed not to replace a person in virtually all spheres of mental activity, but to increase the student's ability to process and perceive information, and to transform the mental activity of the learner.

All didactic principles in-process with computer graphics must be interrelated and interdependent to ensure the most effective work within "the student-computer scheme".

But the introduction of the cognitive visualization theory in educational system is based not only on pedagogical, but also on financial aspects, since it is inextricably linked with the computerization of educational institutions.

All over the world science refers to the costs of development. We regard it as spending budget. Since science and education in our country are not a priority, the industry is financed by a residual principle. This practice for twenty five years had led to large losses. Intellectual losses - more than 200 thousand people left the country", - said Natalia Shulga - the expert of the Reanimation reform package: "Science. Technology. Innovations" [3].

"Now the schools in Kiev are in a more successful condition. They began to massively repair and update the material base. This happened for the first time in many years. But in the regions the situation is deplorable. We must understand that education is now difficult to come without the computerization. Therefore, unfortunately, schools in Ukraine are in unequal conditions", - marks Oksana Oleksuk [3].

Until the computerization of education will not have the proper financial support, many innovative technologies, cognitive graphics including, will not be able to function fully in the educational system of Ukraine. On the other hand, as the introduction of cognitive visualization theory in the education system is inextricably linked with the process of computerization, we should not forget that excessive computer use has not only a lot of advantages, but unfortunately can have a negative impact on a learner's health and psychological development.

"A computer became two-faced Janus, on the one hand it tied a man to itself, on the other, it became the source of 
many diseases connected with the spine, with the respiratory organs, eyesight and many other disorders of the body and this is even though the effect on the body of electromagnetic radiation, insufficient ionization of air and many other factors has not been thoroughly studied, and although people have not known a computer for so many years, they have already begun to acquire the shape of a computer scientist's occupational diseases, this is primarily osteochondrosis, and tunnel syndrome, and visual disorders" [2, p. 1].

In addition to health problems, there are problems of a psychological nature. Along with the advantages of instruction individualization, there is a danger of total individualization. It curtails the already scarce lively dialogue between participants of the educational process-teachers and students, and offers them a surrogate of communication in the form of a computer dialogue. The body of the objectification of human thought-speech is turned off, almost completely immobilized in the learning process.

Thus, if we follow the path of universal computer individualization, we can come to the fact that we will miss the very possibility of forming creative thinking, which in its origin is based on a dialogue.

It should be noted that often quite complex ways of presenting information using multimedia tools can cause a user to be distracted from the studied topic due to problems with using multimedia materials based on hypertext.

Moreover, the multimedia tool is not able to determine the individual needs, as well as the difficulties of each student, and accordingly can not respond to them like a teacher can do.

Taking into account the facts mentioned above, we recommend the introduction of cognitive visualization theory into the learning system through the use of blended teaching techniques, which are based on the parallel use of both innovative methods of computerization and traditional methods of interaction according to the teacher-student scheme.

Conclusion. Summing up, it should be noted that the theory of cognitive visualization is one of the leading forces, allowing to activate the cognitive activity of each student, stimulate the creative development of the personality, initiate the inclusion of previously unclaimed brain resources, facilitating the transfer of emphasis from mastering the necessary knowledge about the object to finding out the mode of action connected with a particular object.

There is no doubt the problem of introducing cognitive graphics into the learning system is $90 \%$ dependent on computerization of education and financial support of innovative programs in Ukraine.

However, it should not be forgotten that excessive computer use during the training process can have a negative impact on the mental and physical development of the student.

Thus, blended learning seems to be most effective technique in training based on cognitive graphics.

Considering the results of the current investigation our further research is aimed at developing the new technological methods based on the theory of cognitive visualization.

\section{LITERATURE}

1. Churichkanich, I. E. The prerequisites of the development of cognitive-graphics theory // The pedagogical sciences: theory, history, innovative technologies, 2017, № 6. P. 237-251.

2. Zolotova, O. The negative computer impact on the person's health and ways of protection. Access mode: nsportal.ru>The Scarlet Sails project $>$.../negativnoe-vozdeysrvie...

3. Oleksuk, O. How they finance education in Ukraine: development or survival. Access mode:

4. Axelrod, R. the structure of Decision: Cognitive Maps of Political Elites. Princeton. University Press, 1976. 404p.

5. Bellingham, W. SPIE Handbook of Microlithography, Micromachining and Microfabrication, Vol. 1: Microlithography // SPIE Optical Engineering Pr., 1997.

6. Wang, Y. The Theoretical Framework of cognitive informatics // International Journal of Cognitive Informatics and Natural Intelligence, 2007, Vol. 1, Number 1. P. 1-27. https://www.segodnya.ua>psychology.

\section{REFERENCES}

1. Churichkanich, I. E. The prerequisites of the development of cognitive-graphics theory // The pedagogical sciences: theory, history, innovative technologies, 2017, № 6. P. 237-251.

2. Zolotova, O. The negative computer impact on the person's health and ways of protection. Access mode: nsportal.ru $>$ The Scarlet Sails project $>$.../negativnoe-vozdeysrvie...

3. Oleksuk, O. How they finance education in Ukraine: development or survival. Access mode:

4. Axelrod, R. the structure of Decision: Cognitive Maps of Political Elites. Princeton. University Press, 1976. 404p.

5. Bellingham, W. SPIE Handbook of Microlithography, Micromachining and Microfabrication, Vol. 1: Microlithography // SPIE Optical Engineering Pr., 1997.

6. Wang, Y. The Theoretical Framework of cognitive informatics // International Journal of Cognitive Informatics and Natural Intelligence, 2007, Vol. 1, Number 1. P. 1-27.

\section{Теория когнитивной визуализации и ее стратегии}

\section{И. Е. Чуричканич}

Аннотация. В статье представлены концептуальные стратегии теории когнитивной визуализации, отраженные в ведущих технологических методах концепции образовательной деятельности. В статье рассматривается педагогический аспект внедрения когнитивной графики в процесс обучения и ключевые проблемы процесса компьютеризации. Дальнейшее исследование и внедрение новых технологических методов, основанных на теории когнитивной визуализации, сделают обучение более эффективным и творческим процессом.

Ключевые слова: технология вспомогательных средств, технология увеличения плотности информации, технология концептуального ядра, технология алгоритмизации, технология многокодовости. 